\title{
Pesticide Contamination in Food: A Review
}

\author{
Shailesh Tayade ${ }^{1}$, Z. P. Patel ${ }^{2}$, D. S. Mutkule ${ }^{3}$ and A. M. Kakde \\ ${ }^{I}$ (Ph.D Scholar, Deptt. of Entomology, N.M. College of Agriculture, N.A.U., Navsari-396 450, Gujarat, India) \\ ${ }^{2}$ (Principal, College of Agriculture, N.A.U., Waghai- 394 730, Gujarat, India) \\ ${ }^{3}$ (Ph.D Scholar, Deptt. of Entomology, N.M. College of Agriculture, N.A.U., Navsari-396 450, Gujarat, India) \\ ${ }^{4}$ (Ph.D Scholar, Deptt. of Entomology, N.M. College of Agriculture, N.A.U., Navsari-396 450, Gujarat, India)
}

\begin{abstract}
The debate on pesticide residues in food in India has raised awareness over contamination of our food commodities with toxic pesticide residues. Unfortunately the debate became restricted to the quality standards and norms pertaining to drinking water and foods at the point of consumption. The more fundamental problem of contamination of all natural resources with chemical pesticide residues because of faulty and hazardous agricultural technologies at the farming level is often ignored. Without solving the basic problem, no amount of standard-setting at the consumption level is going to solve the problem, especially in developing countries where enforcement of regulations is notoriously weak or even absent. Though some pesticides banned, their residues are still persisting/existing in food and environment due to its illegal use and nature of persistence. Therefore, it is essential to fan out the awareness about GAP (Good Agricultural Practices) among the farmers and strict action against the illegal use of pesticides.
\end{abstract}

Keywords: pesticide, residue, fruits, vegetable, legumes, fibre, spices, household processes, GAP

\section{Introduction}

Pesticides are the chemicals used for the control of pest infestation and diseases of crops. Contamination of food commodities with trace amounts of pesticides has become a growing source of concern for the general population. However, the extensive use of pesticides may result into their accumulation in the agricultural produce. Their low biodegradability has classified these chemicals as persistent toxic substances. Pesticides, biological stability and higher degree of lipophilicity in food commodities pose a significant effect on human and animal health. Moreover, organchlorines pesticides have a wide range of acute and chronic health effects, including neurological disruptors and developmental effects in human and animals. The indiscriminate use of pesticides in different crops creates the problems of bio-concentration in the environment. It is well recognized that there are risk attached to the consumption of pesticide treated crops because of the presence of residues on/in them. Therefore, the rational recommendation of pesticides requires that it must not only provide an effective control of pests but at the same time its residues on food commodity must also be toxicologically acceptable. Residue analysis provides measures of the nature and level of any chemical contamination within environment and its persistence. Moreover, based on level of residues in food and food products a GAP (Good Agricultural Practices) can be modified for TQM (Total Quality Management).

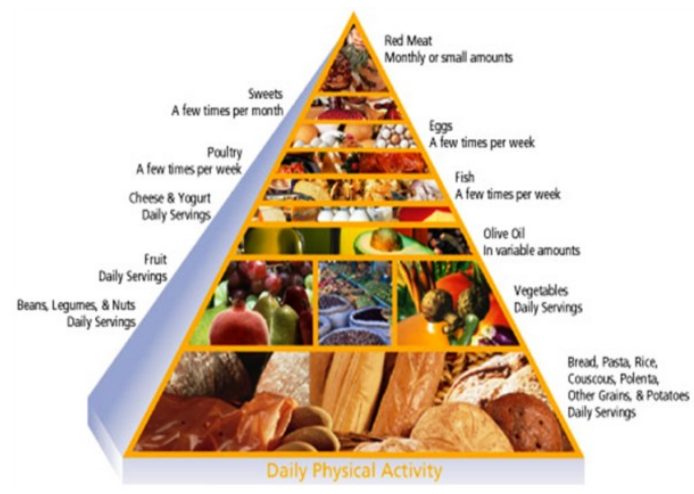

\section{WHAT IS PESTICIDE?}

Pesticide means any substance use for preventing, attracting, repelling or controlling any pest including unwanted species of plants or animals during production, storage, transport, distribution and processing of food or agricultural commodities. 


\section{WHAT IS PESTICIDE RESIDUE?}

The pesticide residue is a substance or mixture of substances in food, feed, soil, water and air originating from the use of pesticides and includes the specified degradation and conversion products, metabolites, reaction products and impurities (Dhaliwal, 2006).

\section{FRUITS AND VEGETABLES}

\section{Pesticide Residues In/On Different Food Commodity}

Dikshit and Mishra (1985) found that the residues of carbaryl and endosulfan persisted above their tolerance limits of 2.00 and $5.00 \mathrm{ppm}$, respectively only up to harvest ( 35 days after spraying) in unprocessed potatoes. In case of endosulfan@ $0.525 \mathrm{~kg}$ a.i./ha, the residues persisted to the level of $2.00 \mathrm{ppm}$ at 65 days (30 days storage).

Reddy et al. (2000) monitored the insecticide residues in market samples of grapes. The residues level of acephate, methamidophos, chlorpyriphos, monocrotophos and quinalphos in var. Thompson seedless were (above MRL), 2.6743, 0.1383, 0.8341, 1.3648 and $0.4132 \mathrm{mg} \mathrm{kg}^{-1}$, respectively. Gajbhiye et al. (2000) showed that the residues of imidacloprid in tomato leaves were persisted up to 30 days after the seed treatment @ $10 \mathrm{~g} / \mathrm{kg}$. While, residues of aforesaid molecule @ 20g/ $\mathrm{kg}$ seed persisted up to 45 days and at 60 days after transplanting, the seedlings were free from residues. The residues of quinalphos on mango was detected till the last sampling ( 15 days) in both concentrations of 0.05 and $0.1 \%$ by imparting 3.30 and 3.32 days as half life and waiting period of 11.50 and 14.20 days, respectively, as suggested by Vijayalakshami (2002).

Arora and Singh (2004) determined the residues of chlorpyriphos and cypermethrin in/on okra and brinjal fruits at harvest in IPM and non-IPM plots. The residues of chlorpyriphos in IPM plots were $\left(0.104 \mu \mathrm{g} \mathrm{g}^{-}\right.$ $\left.{ }^{1}\right)$ not exceeded the MRL $\left(0.2 \mu \mathrm{g} \mathrm{g}^{-1}\right)$ and in non-IPM it was found to be exceeded $\left(5.75 \mu \mathrm{g} \mathrm{g} \mathrm{g}^{-1}\right)$, while, cypermethrin residues were above MRL in non-IPM plots. Moreover, in brinjal, residues of monocrotophos were crossed the level of MRL in non-IPM plots and BDL in IPM. The waiting period and half life of fenazaquine 10 EC @ $100 \mathrm{~g}$ a.i. ha $^{-1}$ in apple fruits were 10.5 and 3.9 days, respectively (1999). Moreover, in 2001, residues of aforesaid treatment were persisted for 25 days and 30 days for fenazaquin @200g a.i. ha ${ }^{-1}$ by showing 13.0 and 4.9 days of waiting period and half life, respectively (Sharma et al., 2006).

According to Mohapatra et al. (2006) residues of lambda-cyhalothrin@15g ha $\mathrm{g}^{-1}$ and $30 \mathrm{~g} \mathrm{ha}^{-1}$ in /on acid lime were persisted for 20 days by imparting 3.4 and 8.0 days as half life and waiting period, respectively. Moreover, in juice samples maximum residues $(0.080$ and $0.130 \mathrm{mg} / \mathrm{kg})$ in both treatments were observed on $10^{\text {th }}$ day. Gupta et al. (2008) proved that residues of bifenthrin @ 25 and 50g a.i. ha ${ }^{-1}$ in okra fruits persisted up to 7 days and degrade to its half life at 1.32 and 1.58 days, respectively. However, fipronil residues @,50 and $100 \mathrm{~g}$ a.i. ha ${ }^{-1}$ showed 0.65 and 1.12 days as half life and 3 days as waiting period, respectively, furthermore, indoxacarb residues found to be highly degradable molecules by imparting 1 day as waiting period. Dissipation pattern of propineb @ $2.0 \mathrm{~kg}$ a.i. ha ${ }^{-1}$ in tomato showed maximum initial deposition, $5.41 \pm 0.13 \mu \mathrm{g} \mathrm{g}^{-1}$ and persisted for 15 days $\left(0.05 \pm 0.13 \mu \mathrm{g} \mathrm{g}^{-1}\right)$ with a half life of 2.23 days and 2.02 days as waiting period in season-I (2005-06), moreover, in season-II, the half life and waiting period of same treatment was 2.28 and 2.02 days, respectively, as indicated by Akhtar (2009). Charan et al. (2010) screened the farm gate vegetables samples for pesticide residues and stated that 1 samples of okra was contaminated with methyl parathion $\left(0.22 \mu \mathrm{g} \mathrm{g}^{-1}\right) \mathrm{which}$ was exceeded the MRL $\left(0.2 \mu \mathrm{g} \mathrm{g}^{-1}\right)$ among 25 samples. In case of brinjal, 4,7 and 2 samples out of 46 were contaminated with monocrotophos, methyl parathion and cypermethrin, respectively.

The degradation kinetics of carbendazim @ 0.05 and $0.1 \%$ in mango fruits showed maximum initial deposition of 2.48 and $5.28 \mathrm{mg} \mathrm{kg}^{-1}$, while it was 1.23 and $2.51 \mathrm{mg} \mathrm{kg}^{-1}$ in mango pulp, respectively. Moreover, up to 12 days the residues of carbendazim found above MRL in treatment of $0.1 \%$ by exhibiting 4.0 days as half life and pre harvest interval of 2.5 and 7.0 days for both doses, as discussed by Bhattacherjee and Panday (2010).

\section{LEGUME CROPS}

Reddy and Divakar (2003) observed the degradation pattern of bifenthrin (@, 0.015\%), chlorpyriphos (@ $0.06 \%$ ) in ground nut stalk. The persistence of bifenthrin residues for both the year were up to 15 days by showing 2.5 and 2.1 days as half life and 2.86 and 2.75 for chlorpyriphos, respectively. Panichar and Jhala (2006) indicated that insecticide residues of endosulfan@0.07, Lambda-cyhalothrin@0.0025, alfamethrin@ 0.01 and fenvalerate @ $0.01 \%$ in first picking of cowpea pods were 0.163, 0.027, 0.0837 and $0.587 \mu \mathrm{g} \mathrm{g} \mathrm{g}^{-1}$, respectively. Whereas, cowpea pods were free from deltamethrin residues due to low application rate $(0.0014 \%)$.

\section{SPICES}

The waiting period of quinalphos@ 0.05 and $0.1 \%$ in fresh and curd cardamom were 23.0 and 24.0 days as well as 20.0 and 21.0 days, respectively. However, waiting period for monocrotophos at same 
concentration was merely same as like quinalphos. Both treatments at aforesaid concentration did not exceed the MRL $\left(0.25 \mathrm{mg} \mathrm{kg}^{-1}\right)$ (Thomas et al., 1998). Kharbade et al. (2003) proved that residues if imidacloprid 17.8 SL @ $100 \mathrm{ml} \mathrm{ha}^{-1}$ persisted up to 3 days, 5 days (@150 $\mathrm{ml} \mathrm{ha}^{-1}$ ) and 7 days for $300 \mathrm{ml} \mathrm{ha}^{-1}$. Mahalingappa et al. (2006) stated that residues of ethion and chlorpyriphos were persisted up to 30 days. Moreover, in dried chillies the residues of both insecticides were found somewhat concentrated. Sandhia and Dubey (2006) detected the residues of pendimethilin and butachlor in green onion, onion bulbs and soil was below MRL $\left(0.025 \mu \mathrm{g} \mathrm{g}^{-1}\right)$.

\section{FIBRE CROPS}

Diwan et al. (2006) stated that residues of $\alpha$ and $\Sigma$ endosulfan in cotton lint were 0.387 and $1.066 \mu \mathrm{g} \mathrm{g}^{-}$ 1 at first picking. While, cotton seed at first and second picking were free from residues. Kanna et al. (2007) revealed that spraying of acetamiprid 20 SP @ 10, 20, 40 and 80g a.i. ha ${ }^{-1}$ did not showed any residues in cotton lint, seed and oil as well as soil.

\section{CUCURBITACEOUS CROPS}

Singh et al. (2007) showed the degradation pattern of ethion @ 375g a.i. ha ${ }^{-1}$ residues in cucumber which were persisted up to 10 days with initial deposition of $2.40 \pm 0.006 \mathrm{mg} \mathrm{kg}^{-1}$. Moreover, waiting period was 7.0 days with 83.3 per cent reduction.

\section{STORED GRAINS}

Rani et al. (2006) reported that residues of deltamethrin in two var. of wheat (HD-2687 and WH-147) were found below MRL at 15 DAT in stored condition. Furthermore, Pal and Shah (2008) showed the half life of chlorpyriphos, fipronil over all, $\Sigma$ endosulfan, lambda-cyhalothrin and deltamethrin were 66.9, 130.9, 86.0, 136.8 and 88.5 , respectively.

\section{DRY FRUIT NUTS}

Pandey et al. (2010) analysed cashew nut, walnut, almond Pistachio nut, coconut, chilgoza, chironji, apricot resins and makhana for endosulfan residues and all the samples are found free from residues.

\section{MEAT}

Vijayan et al. (2006) determined residues of pp' DDT in 17 animals (slaughtered for meat purpose) from Thirunamthpuram, Kollam and Pathanamthitta in variable concentration. The $\mathrm{HCH}(\alpha$ and $\beta)$ and dicofol residues were also seen in meat.

\section{WATER}

Deka et al. (2006) observed the organochlorines residues in water at very low concentration (Below MRL-0.1 ng ml ${ }^{-1}$ ) except endosulfan sulphate, while, residues of SP's and OP's were free from residues.

\section{FISH}

Among the various fish species of ganga river tested for organochlorines residues, the fish species, $R$. rita was found highly contaminated with total organochlorines residues of 7.9-90.4 mg kg-1 (Samanta, 2006). Moreover, on comparing the effect of different herbicides, it was observed that the fish mortality is more with 2,4-DEE and paraquat than with glyphosate (Muniappa et al., 1995).

\section{Effect Of Household Processes}

Beena (2008) stated that household processes like washing and boiling for brinjal, cauliflower and okra found effective in reduction of pesticide residues ( $\Sigma$ - $\mathrm{HCH}, \Sigma$-DDT, $\Sigma$-endosulfan, SP's, OP's and carbamet).
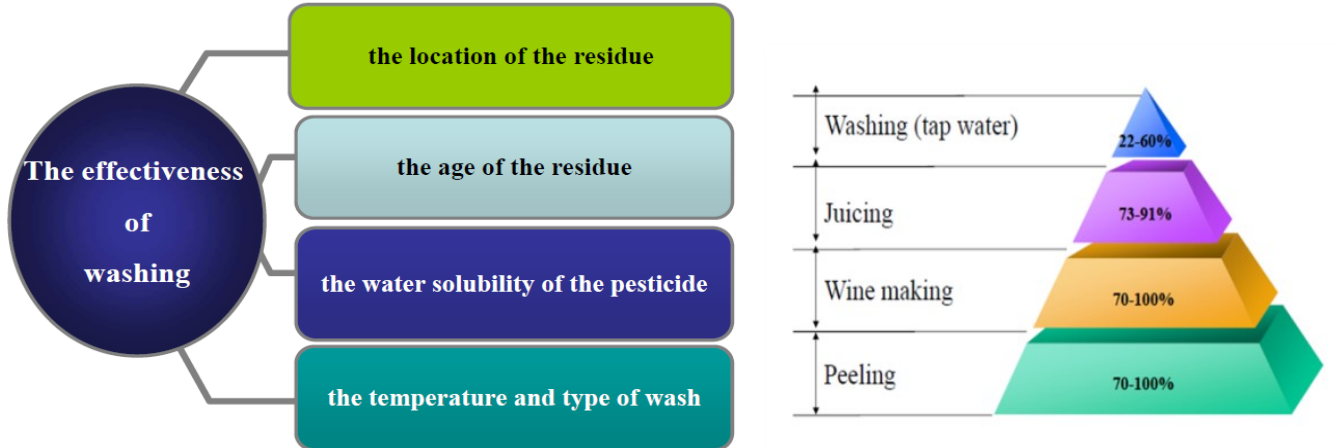

PER CENT REDUCTION OF PESTICIDE RESIDUES IN CULINARY PROCESSES 


\section{Good Agricultural Practices for Management of Pesticide Residues}

* Keep an inventory of all chemicals. Store all chemicals in their original containers. Never store herbicides with other pesticides.

* Always use only recommended pesticides at the specified doses and frequency and at the right time. Never use banned pesticides.

* Education and training in the proper use of pesticides. The improper use or misuse through lack of understanding creates residue problems.

- Unused pesticide solution and washings generated by cleaning spray pumps contain pesticide residue. Dispose of them properly to avoid pollution.

* Avoid indiscriminate use of Pesticides

* Adopt Integrated Pest Management System

* Use of safe pesticides which helps in conserving predators/ parasites

* Strictly follow waiting period before harvesting

- Maintain healthy soil with compost and mulch so that pest problems are minimal.

* Vegetables \& fruits should be thoroughly washed with clean water

* Reduce spray drift in orchards by using lower pressures, larger nozzles and less volatile pesticides and by spraying when there is little or no wind.

* Proper precautions must be taken for the control of house hold insects / stored grain pests.

* Use botanicals / microbial insecticides for the control of various crop pests

* Purchase pesticides only from authorized dealers

* Banned pesticides should not be used for pest control

* Get detailed information from the authorized people before mixing of various pesticides.

* Always read product labels carefully before applying any pesticide, mix and apply as directed.

\section{Conclusion}

Pesticide residues in food pose a significant health effect on human and animals. To provide adequate food for growing population, the usage of pesticide is necessary but dissemination of information regarding food safety, pesticide handling and good agricultural practices (GAP) among farmers is also a dire need. Though, some pesticides of organchlorines are banned, their persistence in various food commodities is still existing. Therefore, strict action is necessary against the illegal use of such pesticides. Moreover, good agricultural practices and household processes are the important and effective tools in minimizing pesticide residues in food commodities.

\section{References}

[1] G.S. Dhaliwal, An Outline Of Entomology (Kalyani Publishers, Ludhiana, 2009).

[2] A. K. Dikshit and S. S. Mishra, Residues of endosulfan and carbaryl in potato tubers at harvest and after storage. Indian J. Plant Prot., 13, 1985, 105-108.

[3] J.D. Reddy, N.B. Rao, and A.M. Sultan, Insecticide Residues in market samples of grape berries. Pestology 16 (9), $2000,17-22$.

[4] V.T. Gajbhiye, Kumar, Rajesh, R.K. Gupta, and Kalpana, Translocation and Persistence of Imidacloprid in Tomato. Pesti. Res. J., $12(1), 2000,127-129$

[5] K.Vijayalakshmi, Dissipation of quinalphos on mango (Mangifera indica) fruit.Trop. Agric., (Trinidad),78 (1), 2002, 39-42.

[6] Sumitra Arora, and D.K. Singh, Determined of Chlorpyriphos and Cypermethrin Residues in/on okra. Pesti. Res. J., 16 (2), 2004, $68-70$.

[7] I.D. Sharma, J.K. Dubey, and S.K. Patyal, Persistence of Fenazaquin in Apple Fruits and Soil. Pesti. Res. J., 18 (1), 2006, 79-81.

[8] S. Mohapatra, D. Sharma, And A. Rekha, Residues of Lambda cyhalothrin in/on Acid Lime (Citrus aurantifolis). Pesti. Res. J., 18 (1), 2006, 74-75.

[9] S. Gupta, R.K. Sharma, R.K. Gupta, S.R. Sinha, R. Singh, and V.T. Gajbhiye, Persistence of new insecticides and their efficacy against insect pests of okra. Bull. Environ. Conta. and Toxico., 8, 2008, 1-9.

[10] S.A. Akhtar, Dissipation and Transloction of Propineb in Tomato. Pesti. Res. J., 22 (2), 2009, $145-147$.

[11] P.D. Charan, S.F. Ali, Kachhawa, Yati and K.C. Sharma, Monitoring of Pesticide Residues in Farmgate Vegetables of Central Aravalli Region of Western India American-Eurasian J. Agric. \& Environ. Sci., 7(3), 2010, 255-258.

[12] A.K. Bhattacherjee, and B.K. Pandey, Dissipation of carbendazim in mango in pre and post harvest treatments. Journal of Plant Protection science., 2 (1), 2010,65-70.

[13] R.A. Reddy, and J. Divakar, Estimation and Dissipation of Bifenthrin and Chlorpyriphos Residues from Groundnut Stalk and Seed. Pestology, 24 (8), 2003, 32-34.

[14] B.K. Panickar, and R.C. Jhala, Residues of Insecticide in/on Coepea Pod. Indian J. Entomology, 68 (3), $2006,311-312$.

[15] B.M. Thomas, A. Visalakshi, S. N. Beevi, P. A. Rajan Asari, and B. Rajgopal, Dissipation of Quinalphos and Monocrotophos Residues in Cardamom. J. Trop. Agric., 36, 1998, 34-36.

[16] S.B. Kharbade, V. D. Kale, and M.D. Dethe, Residues of Imidacloprid on Chilli. Pestology, 17 (1), $2003,18-19$.

[17] P.B. Mahalingappa , K.D. Reddy, K.N. Reddy, and G.V. Subbaratnam, Dissipation of Ethion and Chlorpyriphos Residues in/on Chilli (Capsicum annum L.). Pesti. Res. J.,18 (1), 2006, 72-73.

[18] Shobha Sondhia, and R.P. Dubey, Terminal Residues of Butachlor and Pendimethalin in Onion. Pesti. Res. J., 18 (2), $2006,89-90$.

[19] Kalpana Diwan, P.G. Shah, and M.F. Raj, Pesticide Residues in Cotton Seed and Lint. Pesti. Res. J.,18 (2), $2006,193-195$.

[20] S.S. Kanna, P. Karuppuchamy, S. Kuttalam and S. Chandrasenkaran, Acetamiprid residues in cotton seed, lint and soil. Pestology, $31(8), 2007,28-30$. 
[21] G. Singh, B. Singh, R.S. Battu, G. Jyot, , B. Singh, and B.S. Joia,Persistence of Ethion Residues on Cucumber, Cucumis sativus (Linn.) Using Gas Chromatography with Nitrogen Phosphorus Detector. Bull. Environ. Contam. Toxicol., 79, $2007,437-439$.

[22] R. Rani, B. Kumari, and R.K. Kashyap, Persistence of Deltamethrin in Stored Wheat Grains. Pesti. Res. J., 18 (1), $2006,92-94$.

[23] P. Pal, and P.G. Shah, Effect of Storage and Processing on Dissipation of Five Insecticides on Wheat. Pesti. Res. J., 20 (2), 2008, 253-258.

[24] P. Pandey, R.B. Raizada, and L.P. Srivastava, Level of Organochlorine Pesticide Residues in Dry Fruit Nuts. J. Environ. Biol., 31 (5), 2010, 705-707.

[25] R. Vijayan, Thomas George, S.N. Beevi, and M.O. Kurien, Residues of Organochlorine Insecticides in Meat of Slaughtered Animals in Kerala. Pesti. Res. J., 18 (2), 2006, 228-230.

[26] S.C. Deka, A. Bharuah, and N. Barman, Pesticide Residues in Different Drinking Water Sources of Jorhat District, India. Pesti. Res. J., 18 (2), 2006, 221-224.

[27] S. Samanta, Organochlorine Pesticide Residues in Fish of River Ganga in West Bengal. Pesti. Res. J., 18 (1), $2006,104-108$.

[28] T.V. Muniappa, V. Manjunatha, V.S. Babu, and H.R. Shivkumar, Efficacy of post emergent herbicides on control of water hyacinth (Eichhornia crassipes Mart.) and their effect on fishes, World Weeds, 2 , 1995, 117-121.

[29] Kumari Beena, Effect of household processing on reduction of pesticide residues in vegetables. ARPN J. Agric. Biol. Sci., 3 (4), $2008,46-51$. 